Actions from the daycare audit included editing the electronic record to include a prompt to record the patient's weight or reason for not doing so, which are read coded. A re-audit will be conducted in three months to check maintenance of practice.

\section{P-145 MANAGING CHANGES IN CONDITION: USING A RECTAL ADMINISTRATION CATHETER TO REDUCE HOSPITAL UTILISATION}

Robert Parker. Hospice and Palliative Nurses Association, Pittsburgh, USA

\subsection{6/bmjspcare-2018-hospiceabs. 170}

Background Options to treat patients' change in condition are limited when the oral route is compromised. Parenteral or hypodermoclysis administration of fluids and medication is possible; however, these methods have limitations, and require alternate forms of medications that can be costly. Delays in obtaining orders, equipment and supplies has the potential to increase hospital utilisation.

Aim Pilot research study looking at the feasibility of the intervention to facilitate safe, easy, comfortable and effective enteral hydration and medication delivery via the rectal route, and the ability to treat changes in patients' condition while decreasing the need for parenteral therapy and hospital utilisation.

Results Ten of 10 (100\%) participants completed the study with 11 total use cases. Hydration was effective in all 11 use cases, with all participants tolerating the intervention without signs of discomfort or expulsion of fluids. The APN and attending physician who performed the prospective chart reviews deemed the patient's change in condition serious enough in nine of the 11 use cases to warrant hospital utilisation had an intervention not been successfully performed. Of the nine use cases deemed serious enough to warrant hospital utilisation, seven (78\%) avoided a transfer to an acute setting after successful intervention with the catheter. Each of these patients returned to their previous oral medications and hydration regimen. For the two patients transferred to the hospital it was necessary for acute care services that mandated a transfer and not the failure of the intervention.

Conclusion In all 11 use cases, the catheter provided a safe, easy, comfortable and effective alternative to parenteral and previous enteral delivery options. This intervention may provide an effective and efficient way to treat patients' changes in condition leading to improved quality metrics and reduced hospital utilisation.

\section{P-146 'UNSUNG HEROES NO MORE' HOW THE ADMINISTRATIVE TEAM TRANSFORMS THE PATIENT EXPERIENCE!}

Heather Lee, Pam Jones, Lorraine McDonagh, Jane Hilton, Daniel Monnery, Alison Coackley. Clatterbridge Cancer Centre, Wirral, UK

\subsection{6/bmjspcare-2018-hospiceabs.171}

Enhanced Supportive Care (ESC) promotes earlier implementation of supportive and palliative care within cancer care. It focusses on keeping patients well through treatment and includes the management of physical and psychological symptoms, controlling side effects from anticancer treatment and post-treatment care. (Multinational Association of Supportive Care, 2017). The Clatterbridge Cancer Centre is participating in a pilot of ESC implementation (CA1 Enhanced Supportive Care for Advanced Cancer Patients for Cancer Programme of Care Schemes: NHS England, 2016, updated 2017). Evaluation focuses on clinical outcomes e.g. referral rates and unplanned admissions but these do not encapsulate the complete patient experience.

Often in healthcare the contribution of administrative team members is not acknowledged and yet these roles are essential. In this pilot, dedicated professional administrative support is a key component and has been instrumental in service expansion and development. Key roles include communicating with and supporting patients and their families and providing valuable guidance to other healthcare professionals across the Trust.

The first patient experience of the service is through telephone contact with a member of the team. The friendly professional supportive approach sets the tone for future care. Patient and carer feedback highlights the importance of a single personal point of access for non-clinical information and support from knowledgeable professionals. They advise on common questions such as 'How does ESC fit into my care?' 'Does this affect my other treatment?' or 'Which professionals will I see?' Patients have welcomed the opportunity to discuss their anxieties or concerns about the service and have valued the emotional support, building up rapport with team members.

Professionals within the Trust have highlighted the value of a single point of referral and the expert advice regarding patient eligibility that the team provides. Providing a personal service is important to the team - they are aware of the value they bring and welcome the opportunity to use their skills to directly contribute to patient care and support.

\section{P-147 'SIT UP, GET DRESSED, KEEP MOVING' - APPLYING THE HOSPITAL INITIATIVE TO THE HOSPICE SETTING}

Suzanne Ford-Dunn, Ellie Stedman. St Barnabas House, Worthing, UK

\subsection{6/bmjspcare-2018-hospiceabs.172}

Introduction Bed rest causes accelerated muscle loss in elderly patients: ten days bed rest ages muscle by ten years (Kortebein, Ferrando, Lombeida et al., 2007), most loss is lower limb and occurs in initial days of immobility. Hospitalised elderly patients spend 20 hours in bed, three sitting and just one standing/walking (Brown, 2009): deconditioning is likely. This results in risk of falls, pressure ulcers, functional incontinence and may be the difference between dependence and independence on discharge. Since 2017 an NHS initiative \#endpjparalysis aims to reduce deconditioning using methods such as encouraging patients to dress, social dining, ward tea parties and activities.

Although our hospice inpatients have tailored physiotherapy, we believed the principles of this initiative could be appropriate for inpatients admitted for symptom control or respite.

Aim To increase staff awareness of risks of bed rest and increase the proportion of appropriate patients up, dressed and moving.

Method After baseline audit we held awareness sessions for staff, introduced daily social dining options, tea and cake club and weekend activity hour. Posters/information leaflets ensure patients/carers understand the importance of keeping moving, and that they bring appropriate clothes/footwear with them. 
Results Baseline audit revealed $40 \%$ of patients well enough to get dressed were still in pyjamas at lunchtime. No patient went to the day room to eat. First quarter results to be presented at conference, along with patient and staff feedback.

Conclusion Despite good physio input, the wider hospice teams could do more to increase patient activity and reduce deconditioning. The 'Sit up, get dressed, keep moving' campaign can be/is appropriate for the hospice setting.

\section{Service development, models and collaborative working}

\section{P-148 THE MY CARE CO-ORDINATION TEAM}

Sarah Myford, Elaine Tolliday. Keech Hospice Care, Luton, Bedfordshire

10.1136/bmjspcare-2018-hospiceabs. 173

The co-ordination model came about from a Local Implementation Group which involves many different local professionals from the hospital, community, social care and hospice. The aim was to co-ordinate patient care through a 24 hour advice and support line, acting as the centre point that holds patient medical records. Communicating with patients, relatives, health care professionals both in the community and hospitals. Helping to reduce avoidable hospital admissions and enable patients to remain in their preferred place of care.

The team have built strong relationships with the local hospital, paramedics, community services and GPs. Attending regular meetings within all areas including Respiratory, Rare Neurological and Heart failure MDTs. We hold the medical records for all consented patients on our database (SystmOne).

Weekly data is sent to the local hospital, paramedic services and out of hours GPs about who is known to The My Care Co-ordination Team (MCCT). This ensures they have up to date information; included is DNACPR status and Preferred place of care.

The palliative care support workers provide hospital/hospice discharge visits to ensure transition back into the patient's home is as smooth as possible. This has helped reduce the amount of potential hospital 'bounce backs'. Personal care is provided for patients whilst waiting for a care package to start which assists in rapid discharge from hospital.

Some feedback: patients feel their care is well coordinated, MCCT has helped patients to remain in their preferred place of care. 'We were lost, no idea what to do. MCCT enabled us to make the right decision for our palliative patient', (Paramedic). Patients known to service: 559 with a population of 200 000. Hospital avoidances: 446 year 2017-2018.

The aims for the service in the future are to offer texting services, skyping and a responsive community nursing team to continue to increase hospital avoidances.

\section{P-149 INCREASING RECOGNITION AND SUPPORT FOR ALL IN OR AROUND THE LAST YEAR OF LIFE, AIREDALE'S EXPERIENCE}

\footnotetext{
1,2Linda Wilson, ${ }^{2}$ Elizabeth Procter. ${ }^{1}$ Airedale NHS FT, Steeton, UK; ${ }^{2}$ Sue Ryder Manorlands,
} Oxenhope, UK

10.1136/bmjspcare-2018-hospiceabs. 174
In Airedale, we have been developing end of life care services at a population level, aiming to identify, offer sensitive conversations, document end of life preferences via an EPaCCS template and coordinate care from a 24/7 hub based at an acute hospital (Gold Line). In 2017/18, 76\% of all 'non-sudden' deaths $(56 \%$ all deaths $)$ were supported by Gold Line (assuming 25\% deaths are not preceded by a phase where identification is possible). Training for health professionals in serious illness conversations has been provided, partly via the NHS England Serious Illness Conversation pilot.

Of the patients who were identified as being in the last year (or so) of life, 14\% died in hospital, 69\% in their usual place of residence and $74 \%$ in the preferred place of death. Airedale has the lowest $\%$ of all deaths in hospital in England (33.4\% cf $46.2 \%) .78 \%$ of patients registered to the service have a non-cancer diagnosis and $76 \%$ are NOT known to specialist palliative care services. $42 \%$ have a dementia code in their record and $70 \%$ are aged 80 or over.

Data from the End of Life Intelligence Network shows that in 2015, 69\% of all deaths were on a GP palliative care register and only $4.8 \%$ patients who died had three or more acute hospital admissions in the last 90 days of life (England $6.9 \%)$. Figures are likely to have improved further since then.

Our service is offering coordinated support 24/7 to a large proportion of people dying who are not being supported by specialist palliative care services. High levels of satisfaction are expressed by patients, their carers and professionals. We believe that the provision of a $24 / 7$ support and advice line, supported by an EPaCCS template is helping to encourage identification and thus improve outcomes for many more patients and their families in line with their expressed preferences and in a cost effective way.

\section{P-150 THE GP'S ROLE IN PALLIATIVE CARE: VIEWS AND EXPERIENCES OF PATIENTS WITH CANCER}

${ }^{1}$ Emilie Green, ${ }^{1}$ Heidi Lempp, ${ }^{2}$ Jane Naismith, 'Patrick White. 'King's College London, London, UK; ${ }^{2}$ St Joseph's Hospice, London, UK

\subsection{6/bmispcare-2018-hospiceabs. 175}

Background General practitioners (GPs) are a vital component of palliative care, given their expertise in generalist care, their relationships with patients and families, and their knowledge of available community health and social services. Little is known about how patients understand and experience the role of their GP in delivering palliative care in the community.

Aims To explore patients' views and experiences of: (i) The role of the GP in providing palliative care to adult patients with cancer; (ii) The facilitators and barriers to the GP's ability to fulfil this perceived role.

Design Qualitative data were obtained through face-to-face semi-structured interviews. Thematic and discourse analysis were undertaken.

Setting/participants Adults with a cancer diagnosis and palliative care needs known to an inner-city hospice.

Results Fifteen participants reported actual and desired constituents of the GP's role in palliative care provision, such as: 